\title{
Study of the compatibility of oral magnesium oxide preparations sold in Japan with the ICH-Q3D guideline for elemental impurities
}

\author{
Mitsutoshi Satoh $^{1, *}$, Kimitaka Motokawa ${ }^{1}$, Yoshihiro Uesawa ${ }^{1}$, Yoichi Ishikawa ${ }^{1}$, \\ Hideki Maeda $^{1}$, Katsumi Iida ${ }^{1}$, Hiroyuki Tanaka ${ }^{2}$, Takayoshi Kosugi ${ }^{3}$, Kenji Nishizawa ${ }^{4}$ \\ ${ }^{1}$ Faculty of Pharmaceutical Sciences, Meiji Pharmaceutical University, Tokyo, Japan; \\ ${ }^{2}$ Faculty of Pharmaceutical Sciences, Toho University, Chiba, Japan; \\ ${ }^{3}$ Department of Pharmacy, National Defence Medical College Hospital, Saitama, Japan; \\ ${ }^{4}$ Department of Pharmacy, Omori Medical Center, Toho University, Tokyo, Japan.
}

SUMMARY Magnesium oxide has been widely used as an antacid and constipation remedy. Currently in Japan, magnesium oxide preparations manufactured by five medical companies are marketed as prescribed generic drugs. In this study, we focused on metal elemental impurities present in $330 \mathrm{mg}$ magnesium oxide tablets manufactured by each of these companies. The content of such impurities was determined by atomic absorption spectrometry and inductively coupled plasma mass spectrometry. We confirmed whether the content conformed to the International Conference on Harmonization of Technical Requirements for Registration of Pharmaceuticals for Human Use, Guideline for Elemental Impurities (ICH-Q3D) based on the 30\% control threshold. The content of these impurities varied among the five products (preparations A-E), but in all cases met the oral permitted daily exposure (PDE) criteria stipulated in ICH-Q3D. In 5 lots of preparation $\mathrm{C}$ and all lots of preparation $\mathrm{D}$, the equivalent cadmium $(\mathrm{Cd})$ intake for a daily maximum dosage of $2 \mathrm{~g}$ was higher than the $30 \%$ control threshold of $1.5 \mu \mathrm{g} /$ day. By cluster analysis, preparations A-E were classified into preparations $\mathrm{A}+\mathrm{B}$ and $\mathrm{C}+\mathrm{D}+\mathrm{E}$ and/or preparations $\mathrm{A}+\mathrm{B}, \mathrm{C}+\mathrm{D}$ and $\mathrm{E}$. The present study showed that all 5 preparations sold in Japan meet the PDE value standard of ICH-Q3D, and that preparations A and B meet the 30\% control threshold. It is important that for preparations failing to meet the criteria, further improvements need to be sought, and impurities in magnesium oxide preparations need to be monitored to ensure their safety.

Keywords Magnesium oxide, metal impurity, ICH-Q3D, control threshold, cluster analysis

\section{Introduction}

In Japan, magnesium oxide preparations are widely used as low-priced, non-addictive laxatives, and can be used relatively safely by pregnant women and children. With long-term administration, however, it is necessary to pay attention to cumulative effects of any impurities, particularly metal impurities, in the preparation. In addition, for use by pregnant women and children, it is important to comply with the stipulated standards for impurities, as in such cases higher-purity preparations are required.

In recent years, due to globalization of the pharmaceutical market, the need for international risk assessment of metal impurities has been discussed at the International Conference on Harmonization of Technical
Requirements for Registration of Pharmaceuticals for Human Use (ICH). Therefore, the ICH Guideline for Elemental Impurities (ICH-Q3D) for oral preparations has been studied. Table 1 shows the permitted daily exposure (PDE) and control threshold for elemental metal impurities regulated by the ICH-Q3D guidelines in pharmaceutical products. They are grouped into 4 classes based on the toxicity of each element and the likelihood of them appearing as contaminants in pharmaceutical products (1). Elemental metal impurities in preparations can originate from not only the drug substance itself and additives, but also several factors such as the materials and containers used in the manufacturing process and the abundance of the elements themselves in nature (1). Class 1 cadmium (Cd), lead (Pb), arsenic (As) and mercury $(\mathrm{Hg})$ are highly toxic elements and are subject 
Table 1. Oral PDE and 30\% control threshold for metals in ICH-Q3D

\begin{tabular}{|c|c|c|c|c|c|}
\hline Class (Toxicity) & Element & $\begin{array}{l}\text { Oral PDE } \\
(\mu \mathrm{g} / \text { day })\end{array}$ & $\begin{array}{l}\text { Oral concentration } \\
(\mu \mathrm{g} / \mathrm{g})[\text { Option } 1]\end{array}$ & $\begin{array}{l}\text { Maximum daily intake in } \\
2 \mathrm{~g} / \text { day }(\mu \mathrm{g} / \mathrm{g}) \text { [Option 3] }\end{array}$ & $\begin{array}{c}30 \% \text { Control threshold in } \\
2 \mathrm{~g} / \text { day }(\mu \mathrm{g} / \mathrm{g})\end{array}$ \\
\hline 1 & $\mathrm{Cd}$ & 5 & 0.5 & 2.5 & 0.75 \\
\hline \multirow{3}{*}{ (Strong) } & $\mathrm{Pd}$ & 5 & 0.5 & 2.5 & 0.75 \\
\hline & As & 15 & 1.5 & 7.5 & 2.25 \\
\hline & $\mathrm{Hg}$ & 30 & 3 & 15 & 4.5 \\
\hline $2 \mathrm{~A}$ & Co & 50 & 5 & 25 & 7.5 \\
\hline \multirow[t]{2}{*}{ (Moderate) } & $\mathrm{V}$ & 100 & 10 & 50 & 15 \\
\hline & $\mathrm{Ni}$ & 200 & 20 & 100 & 30 \\
\hline $2 \mathrm{~B}$ & $\mathrm{Tl}$ & 8 & 0.8 & 4 & 1.2 \\
\hline \multirow[t]{9}{*}{ (Moderate) } & $\mathrm{Au}$ & 100 & 10 & 50 & 15 \\
\hline & $\mathrm{Pd}$ & 100 & 10 & 50 & 15 \\
\hline & $\mathrm{Ir}$ & 100 & 10 & 50 & 15 \\
\hline & Os & 100 & 10 & 50 & 15 \\
\hline & $\mathrm{Rh}$ & 100 & 10 & 50 & 15 \\
\hline & $\mathrm{Ru}$ & 100 & 10 & 50 & 15 \\
\hline & $\mathrm{Pt}$ & 100 & 10 & 50 & 15 \\
\hline & $\mathrm{Se}$ & 150 & 15 & 75 & 22.5 \\
\hline & $\mathrm{Ag}$ & 150 & 15 & 75 & 22.5 \\
\hline 3 & $\mathrm{Li}$ & 550 & 55 & 275 & 82.5 \\
\hline \multirow[t]{6}{*}{ (Moderate) } & $\mathrm{Sb}$ & 1,200 & 120 & 600 & 180 \\
\hline & $\mathrm{Ba}$ & 1,400 & 140 & 700 & 210 \\
\hline & Mo & 3,000 & 300 & 1,500 & 450 \\
\hline & $\mathrm{Cu}$ & 3,000 & 300 & 1,500 & 450 \\
\hline & $\mathrm{Sn}$ & 6,000 & 600 & 3,000 & 900 \\
\hline & $\mathrm{Cr}$ & 11,000 & 1,100 & 5,500 & 1,650 \\
\hline
\end{tabular}

PDE: permitted daily exposure.

to the strictest regulatory values. Class 2 elements are those that exhibit toxicity depending on the route of administration. Class 2A cobalt (Co), vanadium (V), and nickel (Ni) are considered highly likely to be present in pharmaceutical products, and therefore risk assessment is essential. It is necessary to prove that Class $2 \mathrm{~B}$ and Class 3 elements, which are considered unlikely to be present in pharmaceutical products, are below the regulated values when used in catalysts, etc. during the manufacture of pharmaceutical products (1). ICH-Q3D stipulates four options - 1, 2a, 2b, and 3 - as risk evaluation methods. Option 1 involves setting an allowable concentration limit for a common element among the components of a drug with a daily intake of 10 grams or less. Option 2a involves setting the permissible concentration limit for an element among the components of a drug for which the daily intake is specified. Option $2 \mathrm{~b}$ involves setting the permissible concentration limit of elements among the individual components of a product for which the daily intake is specified. Option 3 involves confirming that the elements present in the final product are below the permissible concentration limit (1).

As shown in Table 1, Cd and Pb have a PDE of $5 \mu \mathrm{g} /$ day for a body weight of $50 \mathrm{~kg}$. In Japan, a maximum of $2 \mathrm{~g}$ of magnesium oxide is taken daily for constipation (2). Therefore, when $2.5 \mu \mathrm{g}$ of $\mathrm{Cd}$ and $\mathrm{Pb}$ is mixed in a preparation containing $1 \mathrm{~g}$ of magnesium oxide, the standard is exceeded. Cd causes Itai-itai disease at high concentrations, but it accumulates in the kidneys and liver stores eve at even low concentrations and is highly toxic (3). $\mathrm{Pb}$ has a half-life of about 28 - 36 days in blood and soft tissues, but disappears when taken up by bone and has a long half-life in the order of years (4). In addition, the in vivo stagnation rate of $\mathrm{Pb}$ is higher in children than in adults. A concentration of $10 \mu \mathrm{g} / \mathrm{dL}$ causes acute poisoning of the blood and nervous system, and long-term exposure also results in chronic poisoning symptoms such as angiopathy, neuropathy and cerebral edema, as well as carcinogenicity and reproductive and developmental toxicity (5).

We have previously reported the results of a pilot survey of the content of heavy metal impurities in magnesium oxide preparations, pointing out differences between the preparations (6). In the present study, the actual condition of metal impurities contained in multiple magnesium oxide preparations sold in Japan was investigated in detail by analyzing the final products. Then, in consideration of the control threshold according to option 3 recommended by ICH-Q3D, the suitability of applying the ICH-Q3D standard to the preparations sold in Japan was examined. Furthermore, we used cluster analysis to examine the risk classification of the drugs.

\section{Materials and Methods}

\subsection{Survey preparation}

In April 2020, various dosage forms of magnesium 
Table 2. The magnesium oxide formulations available on the Japanese market chosen for the study

\begin{tabular}{|c|c|c|c|c|c|c|c|}
\hline \multirow{2}{*}{ Preparation } & \multicolumn{7}{|c|}{ Formulation } \\
\hline & 200 mg Tablet & $250 \mathrm{mg}$ Tablet & $300 \mathrm{mg}$ Tablet & 330 mg Tablet & $400 \mathrm{mg}$ Tablet & 500 mg Tablet & Fine Granules $83 \%$ \\
\hline A & $\circ$ & ○ & & ० & & ० & ० \\
\hline B & & ० & & ० & & ○ & \\
\hline $\mathrm{C}$ & o & ० & ○ & o & ○ & ○ & ○ \\
\hline $\mathrm{D}$ & & ○ & & ० & & ० & ० \\
\hline $\mathrm{E}$ & & $\circ$ & & ० & & & \\
\hline
\end{tabular}

oxide preparations commercially available from 5 pharmaceutical companies (Kenei Pharmaceutical Co. Ltd., Osaka, Japan; Kyowa Chemical Industry Co. Ltd., Kagawa, Japan; Mochida Pharmaceutical Co. Ltd., Tokyo, Japan; Mylan, Tokyo, Japan; Yoshida Pharmaceutical Co. Ltd., Tokyo, Japan) were obtained (Table 2). Among those preparations, $330 \mathrm{mg}$ tablet formulations of magnesium oxide were targeted for the research. Six different lots marketed between 2018 and 2020 were used.

\subsection{Tablet weight measurement}

Sixty tablets from each lot of each company's preparation were collected and weighed.

\subsection{Quantitative analysis of $\mathrm{Cd}$ and $\mathrm{Pb}$}

Tablets of each preparation were crushed, and after acid treatment of $1 \mathrm{~g}$ of the powder, the sample was heated in a muffle furnace at $600^{\circ} \mathrm{C}$ for 3 hours. The incinerated sample was then dissolved in acid to make a $30 \mathrm{~mL}$ solution. The supernatant was separated and the pH adjusted to 5 with $20 \%$ aqueous ammonia and $70 \%$ nitric acid. The liquid was passed through a chelate resin Novia Skilate column (CHELATE-PA1, Hitachi High-Tech Science Corp., Tokyo, Japan), and Cd and $\mathrm{Pb}$ were adsorbed and separated from the matrix metal $\mathrm{Mg}$. $\mathrm{Cd}$ and $\mathrm{Pb}$ on the chelate resin were then eluted off with $3 \mathrm{~N}$ nitric acid solution to prepare a measurement solution. Inductively coupled plasma mass spectrometry (ICP-MS) (ELAN DRC II, PerkinElmer Japan Co. Ltd., Kanagawa, Japan) was used to quantify $\mathrm{Cd}$ and $\mathrm{Pb}$ by the ICP-MS method employing absolute calibration.

\subsection{Quantitative analysis of As}

Tablets of each preparation were crushed and $0.5 \mathrm{~g}$ of the powder was collected, followed by addition of $5 \mathrm{~mL}$ of sulfuric acid : nitric acid $(1: 1)$ and heat treatment. Then $4 \mathrm{~mL}$ of $20 \%$ potassium iodide solution was added, the volume was adjusted to $50 \mathrm{~mL}$, and the mixture was left at room temperature for 1 hour. After being allowing to cool, As was quantified using the absolute calibration curve obtained by hydride generation atomic absorption spectrophotometry (AA-
7000, Shimadzu Corp., Kyoto, Japan).

\subsection{Quantitative analysis of $\mathrm{Hg}$}

Tablets of each preparation were crushed and $1 \mathrm{~g}$ of the powder was subjected to acid treatment, followed by addition of a solution of sulfuric acid, nitric acid and potassium permanganate and heat treatment. After being allowing to cool, $\mathrm{Hg}$ was quantified using the absolute calibration curve obtained by the reduced vaporization atomic absorption method using a mercury measurement device (HG-400, HIRANUMA Co. Ltd., Ibaraki, Japan).

\subsection{Quantitative analysis of Co, Ni, V, Sn and Cr}

Tablets of each preparation were crushed and $1 \mathrm{~g}$ of the powder was subjected to acid treatment, followed by heating in a muffle furnace at $600^{\circ} \mathrm{C}$ for 3 hours. The incinerated sample was then dissolved in acid to make $30 \mathrm{~mL}$ of solution. The supernatant was separated and ICP-MS (ELAN DRC II, PerkinElmer Japan Co. Ltd.) was used to quantify $\mathrm{Co}, \mathrm{Ni}, \mathrm{V}, \mathrm{Sn}$ and $\mathrm{Cr}$ by the ICPMS method using absolute calibration.

\subsection{Reagents}

ICP-MS analysis standard solution, Cd standard solution, $\mathrm{Pb}$ standard solution, As standard solution, $\mathrm{Hg}$ standard solution, and Sn standard solution were obtained from FUJIFILM Wako Chemical Corp. (Miyazaki, Japan). For the $\mathrm{Co}, \mathrm{Ni}, \mathrm{V}, \mathrm{Sn}$, and $\mathrm{Cr}$ mixed standard solution, a mixed standard solution for ICP-MS analysis was obtained from SPEX (New Jersey, USA). Sulfuric acid, nitric acid, potassium permanganate solution, potassium iodide solution and other reagents (FUJIFILM Wako Chemical Corp.) used were analytical grade. The water used was ultrapure.

\subsection{Calculation of acceptable daily intake (ADI)}

For $\mathrm{Cd}, \mathrm{Pb}$, and $\mathrm{As}$, ADI was calculated using the following formula based on the quantitative results for each formulation.

$\operatorname{ADI}(\mathrm{g} /$ day $)=$ Oral PDE $(\mu \mathrm{g} /$ day $) / \operatorname{Impurity}(\mu \mathrm{g} / \mathrm{g})$ 
2.9. Characterization of heavy metals present in magnesium oxide preparations using cluster analysis

Cluster analysis was performed using JMP Pro13.2.0 (SAS Institute Inc. NC, USA). The heavy metal contents were used to interpret the characteristics of magnesium oxide preparations. Hierarchical cluster analysis was used to classify the magnesium oxide preparations objectively. This analysis used the Ward method based on Euclidean distance from the heavy metal contents. The hierarchical cluster analysis established two clusters.

\subsection{Statistics}

The experimental data are shown as mean \pm standard error (SE). One-way ANOVA and Tukey's multiple comparison method were used to test the differences in means between each group using JMP Pro13.2.0 (SAS Institute Inc. NC, USA). The significance level was set at $p<0.05$.

\section{Results}

3.1. Comparison of weight of each tablet and magnesium oxide content per gram of preparation

The measured weights of the tablets for the 6 lots of magnesium oxide preparations manufactured by drug companies A, B, C, D and E, respectively, are shown in Table 3. There was no significant difference in mass between the preparations, and the differences were all within $10 \%$.

Table 3. Tablet weights of magnesium oxide preparations and their magnesium oxide contents

\begin{tabular}{lcc}
\hline Preparation & $\begin{array}{c}\text { Weight of tablet } \\
(\mathrm{g} / \text { tablet })\end{array}$ & $\begin{array}{c}\text { Contents of magnesium oxide } \\
(\mathrm{g} / 1 \mathrm{~g})\end{array}$ \\
\hline $\mathrm{A}$ & $0.378[0.376-0.378]$ & $0.882[0.880-0.885]$ \\
$\mathrm{B}$ & $0.395[0.394-0.397]$ & $0.843[0.838-0.846]$ \\
$\mathrm{C}$ & $0.396[0.396-0.397]$ & $0.841[0.839-0.841]$ \\
$\mathrm{D}$ & $0.408[0.406-0.410]$ & $0.816[0.811-0.820]$ \\
$\mathrm{E}$ & $0.402[0.401-0.403]$ & $0.829[0.826-0.831]$ \\
\hline
\end{tabular}

$n=6$, mean [range].
3.2. Comparison of metal element impurities per gram of each preparation

Table 4 shows the measured contents of elemental metal impurities contained in preparations A, B, C, D and $\mathrm{E}$. The content of elemental metal impurities varied depending on the preparation, but all of them conformed to the PDE value defined by ICH-Q3D.

The PDE value for Cd in Class 1 is defined as $5 \mu \mathrm{g} /$ day. The Cd contents of preparations A and B were less than $0.02 \mu \mathrm{g} / \mathrm{g}$ and $0.01 \mu \mathrm{g} / \mathrm{g}$, respectively, being significantly lower than those in preparations C, D and $\mathrm{E}(p<0.05)$. The $\mathrm{PDE}$ value for $\mathrm{Pb}$ is $5 \mu \mathrm{g}$ /day. The $\mathrm{Pb}$ contents of preparations C, D and E were $0.18 \mu \mathrm{g} / \mathrm{g}, 0.13$ $\mu \mathrm{g} / \mathrm{g}$ and $0.12 \mu \mathrm{g} / \mathrm{g}$, respectively, being significantly higher than those in preparations $\mathrm{A}$ and $\mathrm{B}(p<0.05)$. The PDE value for As is $15 \mu \mathrm{g} /$ day. The As contents of preparations C, D and E were $1.57 \mu \mathrm{g} / \mathrm{g}, 1.27 \mu \mathrm{g} / \mathrm{g}$ and $1.70 \mu \mathrm{g} / \mathrm{g}$, respectively, being significantly higher than those in preparations A and B $(p<0.05)$. The PDE value for $\mathrm{Hg}$ is $30 \mu \mathrm{g} / \mathrm{day}$. The $\mathrm{Hg}$ contents of all the preparations were below the measurement limit of 0.05 $\mu \mathrm{g} / \mathrm{g}$.

The PDE value for Class $2 \mathrm{~A}$ Co is $50 \mu \mathrm{g} /$ day. The Co content was below the measurement limit of $0.50 \mu \mathrm{g} / \mathrm{g}$ in all the preparations. The PDE value for $\mathrm{V}$ is $100 \mu \mathrm{g} / \mathrm{day}$. The $\mathrm{V}$ content of preparation E was $3.12 \mu \mathrm{g} / \mathrm{g}$, which was the highest. The V contents of preparations C, D and E were significantly higher than those in preparations $\mathrm{A}$ and $\mathrm{B}$, respectively $(p<0.05)$. The PDE value for $\mathrm{Ni}$ is $200 \mu \mathrm{g} /$ day. The Ni content of preparation $\mathrm{E}$ was the highest, at $2.55 \mu \mathrm{g} / \mathrm{g}$. The Ni contents of preparations $\mathrm{C}, \mathrm{D}$ and $\mathrm{E}$ were significantly higher than those of preparations A and $\mathrm{B}(p<0.05)$.

The PDE value for Class $3 \mathrm{Sn}$ is $6,000 \mu \mathrm{g} /$ day. The Sn content of all preparations was less than $0.50 \mu \mathrm{g} / \mathrm{g}$. The PDE value for $\mathrm{Cr}$ is $11,000 \mu \mathrm{g} / \mathrm{day}$. The $\mathrm{Cr}$ content was highest in preparation $\mathrm{E}$, at $6.12 \mu \mathrm{g} / \mathrm{g}$.

3.3. Comparison of heavy metal element impurity contents of various magnesium oxide formulations at maximum daily dose

ICH-Q3D defines an accurate risk assessment process

Table 4. Pharmaceutical data for elemental impurities in $1 \mathrm{~g}$ magnesium oxide preparations

\begin{tabular}{|c|c|c|c|c|c|c|}
\hline Element & Oral PDE ( $\mu \mathrm{g} /$ day) & A & $\mathrm{B}$ & $\mathrm{C}$ & $\mathrm{D}$ & $\mathrm{E}$ \\
\hline $\mathrm{Cd}$ & 5 & $0.02 \pm 0.00$ & $0.01 \pm 0.00$ & $0.71 \pm 0.05$ & $0.83 \pm 0.12$ & $0.26 \pm 0.02$ \\
\hline $\mathrm{Pb}$ & 5 & $0.02 \pm 0.00$ & $0.02 \pm 0.00$ & $0.18 \pm 0.01$ & $0.13 \pm 0.01$ & $0.12 \pm 0.01$ \\
\hline As & 15 & $<0.10$ & $<0.10$ & $1.57 \pm 0.10$ & $1.27 \pm 0.04$ & $1.70 \pm 0.16$ \\
\hline $\mathrm{Hg}$ & 30 & $<0.05$ & $<0.05$ & $<0.05$ & $<0.05$ & $<0.05$ \\
\hline $\mathrm{Co}$ & 50 & $<0.50$ & $<0.50$ & $<0.50$ & $<0.50$ & $<0.50$ \\
\hline $\mathrm{V}$ & 100 & $<0.50$ & $<0.50$ & $2.47 \pm 0.11$ & $2.75 \pm 0.41$ & $3.12 \pm 0.51$ \\
\hline $\mathrm{Ni}$ & 200 & $0.68 \pm 0.05$ & $1.18 \pm 0.05$ & $1.97 \pm 0.11$ & $2.33 \pm 0.27$ & $2.55 \pm 0.15$ \\
\hline $\mathrm{Sn}$ & 6,000 & $<0.50$ & $<0.50$ & $<0.50$ & $<0.50$ & $<0.50$ \\
\hline $\mathrm{Cr}$ & 11,000 & $<0.50$ & $2.93 \pm 0.48$ & $4.25 \pm 0.19$ & $5.78 \pm 0.57$ & $6.12 \pm 0.19$ \\
\hline
\end{tabular}

$n=6$, mean $\pm \mathrm{SE}(\mu \mathrm{g} / \mathrm{g})$, PDE: permitted daily exposure. 
by setting a $30 \%$ control threshold to ensure that the elements present in the product are below the permissible concentration PDE. In this study, the content of metal element impurities at the maximum daily dose of $2 \mathrm{~g}$ (Option 3) of magnesium oxide described in the attached document was compared for 6 lots of preparations A-E based on the $30 \%$ control threshold (Figure 1). In 5 lots of preparation $\mathrm{C}$ and all lots of preparation $\mathrm{D}, \mathrm{Cd}$ present as a metal element impurity in the maximum daily dose of $2 \mathrm{~g}$ of magnesium oxide showed a value higher than the 30\% control threshold (Figure 1a).

Table 5 shows the $30 \%$ control threshold value at the maximum daily dose of $2 \mathrm{~g}$ of magnesium oxide and the contents of the metal element impurities in 6 lots of preparations A to E. The underlined numbers indicate values that exceed the $30 \%$ control threshold.

3.4. Risk classification of preparations by cluster analysis

A cluster analysis was performed based on the data in a

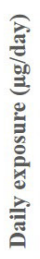

Class 1 Cd impurities
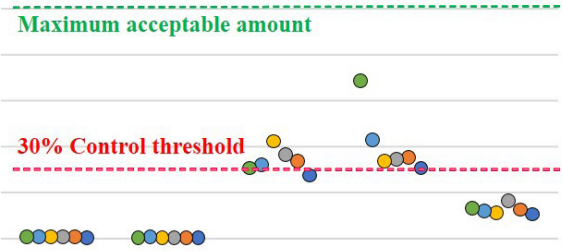

A

B

C

D

E

C

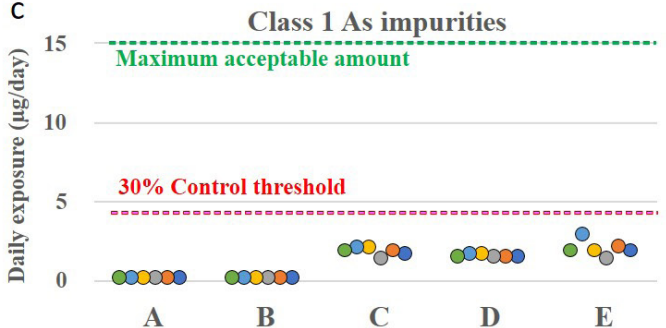

A

Class 2A Co impurities
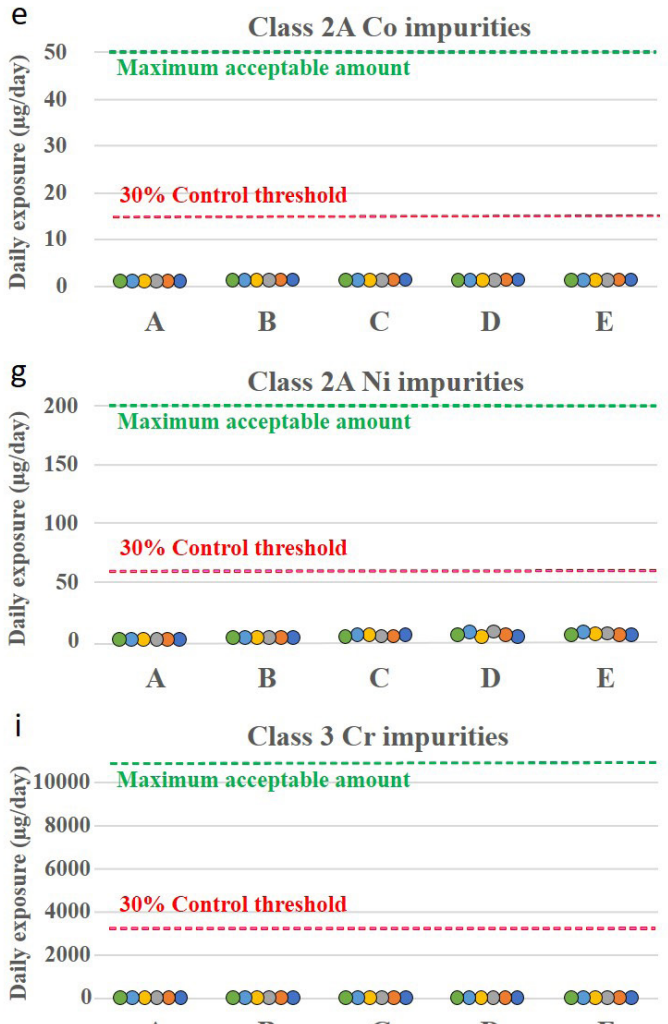

A

B

C

D

E
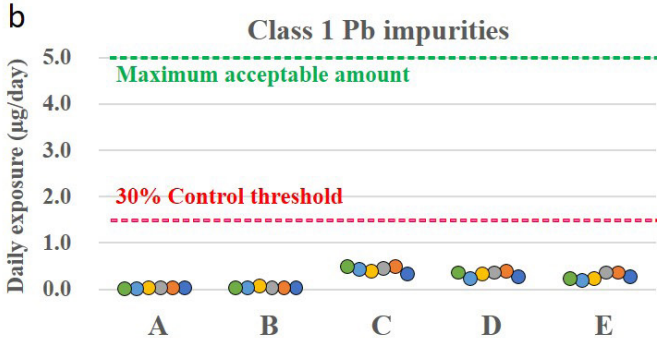

d

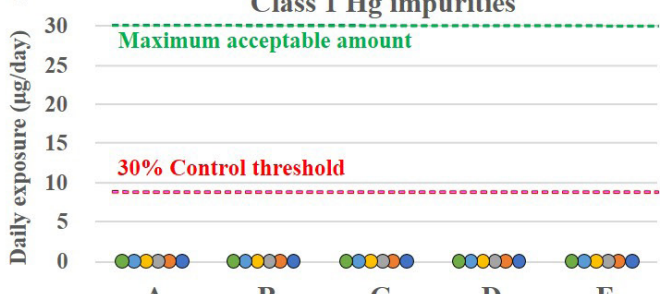

Class $1 \mathrm{Hg}$ impurities

$\begin{array}{lllll}\text { A } & \text { B } & \text { C } & \text { D } & \text { E }\end{array}$

f

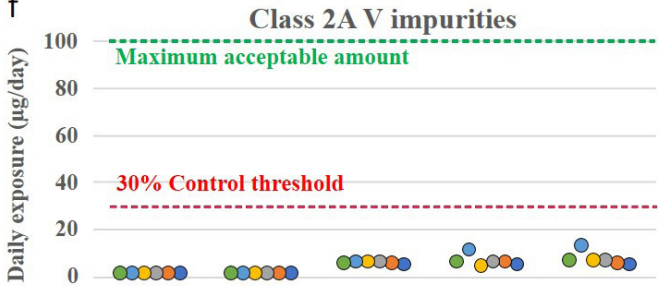

$\begin{array}{llllll}\text { A } & \text { B } & \text { C } & \text { D } & \text { E }\end{array}$

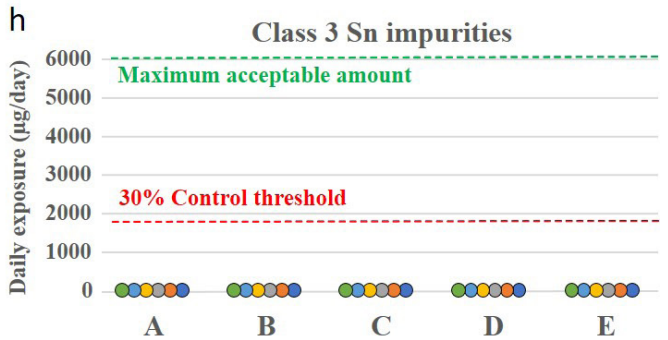

Figure 1. Heavy metal contents of the various magnesium oxide formulations for maximum daily administration. The ordinates represent daily intake exposure for each heavy metal element at the maximum daily dose of $2 \mathrm{~g}$ magnesium oxide. Abscissae represent preparations A-E. Each point represents one lot of each preparation. Green line indicates acceptable maximum daily intake, and red line indicates the $30 \%$ control threshold based on oral PDE at maximum daily dose of $2 \mathrm{~g}$ magnesium oxide. 
Table 5. Pharmaceutical data for elemental impurities in magnesium oxide preparation at a maximum daily dose of $2 \mathrm{~g}$

\begin{tabular}{|c|c|c|c|c|c|c|}
\hline Element & $30 \%$ Control threshold ( $\mu \mathrm{g} /$ day) & A & B & $\mathrm{C}$ & $\mathrm{D}$ & $\mathrm{E}$ \\
\hline $\mathrm{Cd}$ & 1.5 & $\begin{array}{c}0.05 \pm 0.01 \\
{[0.02-0.05]}\end{array}$ & $\begin{array}{c}0.03 \pm 0.01 \\
{[0.02-0.05]}\end{array}$ & $\begin{array}{l}\underline{1.68} \pm 0.11 \\
{[1.35-\underline{2.12}]}\end{array}$ & $\begin{array}{c}\underline{2.04} \pm 0.39 \\
{[\underline{1.51}-\underline{3.43}]}\end{array}$ & $\begin{array}{c}0.63 \pm 0.04 \\
{[0.51-0.82]}\end{array}$ \\
\hline $\mathrm{Pb}$ & 1.5 & $\begin{array}{c}0.04 \pm 0.01 \\
{[0.02-0.05]}\end{array}$ & $\begin{array}{c}0.05 \pm 0.01 \\
{[0.05-0.07]}\end{array}$ & $\begin{array}{c}0.42 \pm 0.03 \\
{[0.31-0.50]}\end{array}$ & $\begin{array}{c}0.32 \pm 0.03 \\
{[0.22-0.39]}\end{array}$ & $\begin{array}{c}0.28 \pm 0.02 \\
{[0.19-0.36]}\end{array}$ \\
\hline As & 4.5 & $<0.20$ & $<0.20$ & $\begin{array}{c}1.85 \pm 0.11 \\
{[1.40-2.10]}\end{array}$ & $\begin{array}{c}1.57 \pm 0.05 \\
{[1.50-1.70]}\end{array}$ & $\begin{array}{c}2.03 \pm 0.20 \\
{[1.40-2.90]}\end{array}$ \\
\hline $\mathrm{Hg}$ & 9 & $<0.10$ & $<0.10$ & $<0.10$ & $<0.10$ & $<0.10$ \\
\hline Co & 15 & $<1.0$ & $<1.0$ & $<1.0$ & $<1.0$ & $<1.0$ \\
\hline $\mathrm{V}$ & 30 & $<1.0$ & $<1.0$ & $\begin{array}{c}5.88 \pm 0.29 \\
{[5.00-6.70]}\end{array}$ & $\begin{array}{c}6.75 \pm 1.04 \\
{[4.40-11.60]}\end{array}$ & $\begin{array}{c}7.53 \pm 1.25 \\
{[5.10-13.50]}\end{array}$ \\
\hline $\mathrm{Ni}$ & 60 & $\begin{array}{c}1.57 \pm 0.10 \\
{[1.40-2.00]}\end{array}$ & $\begin{array}{c}2.80 \pm 0.15 \\
{[2.40-3.30]}\end{array}$ & $\begin{array}{c}4.67 \pm 0.32 \\
{[4.00-5.70]}\end{array}$ & $\begin{array}{c}5.72 \pm 0.69 \\
{[4.10-8.10]}\end{array}$ & $\begin{array}{c}6.17 \pm 0.39 \\
{[5.10-7.00]}\end{array}$ \\
\hline $\mathrm{Sn}$ & 1,800 & $<1.0$ & $<1.0$ & $<1.0$ & $<1.0$ & $<1.0$ \\
\hline $\mathrm{Cr}$ & 3,300 & $<1.0$ & $\begin{array}{l}6.98 \pm 1.22 \\
{[3.10-10.70]}\end{array}$ & $\begin{array}{l}10.12 \pm 0.59 \\
{[8.10-11.20]}\end{array}$ & $\begin{array}{l}14.20 \pm 1.41 \\
{[9.10-19.50]}\end{array}$ & $\begin{array}{c}14.72 \pm 0.45 \\
{[14.00-16.80]}\end{array}$ \\
\hline
\end{tabular}

$n=6$, mean \pm SE [range] $(\mu \mathrm{g} /$ day), $30 \%$ Control thresholds are calculated from PDE, underbars represents value over $30 \%$ control threshold.

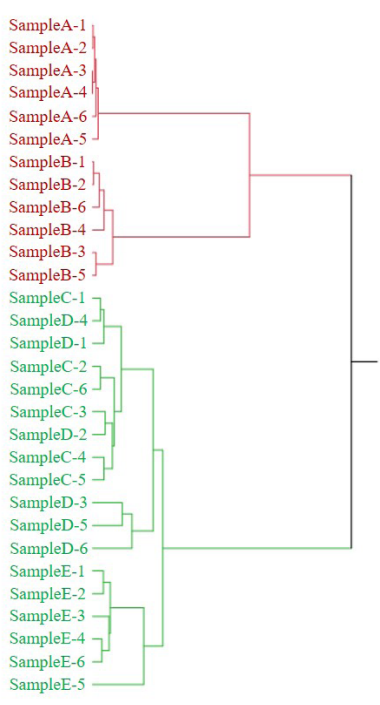

b

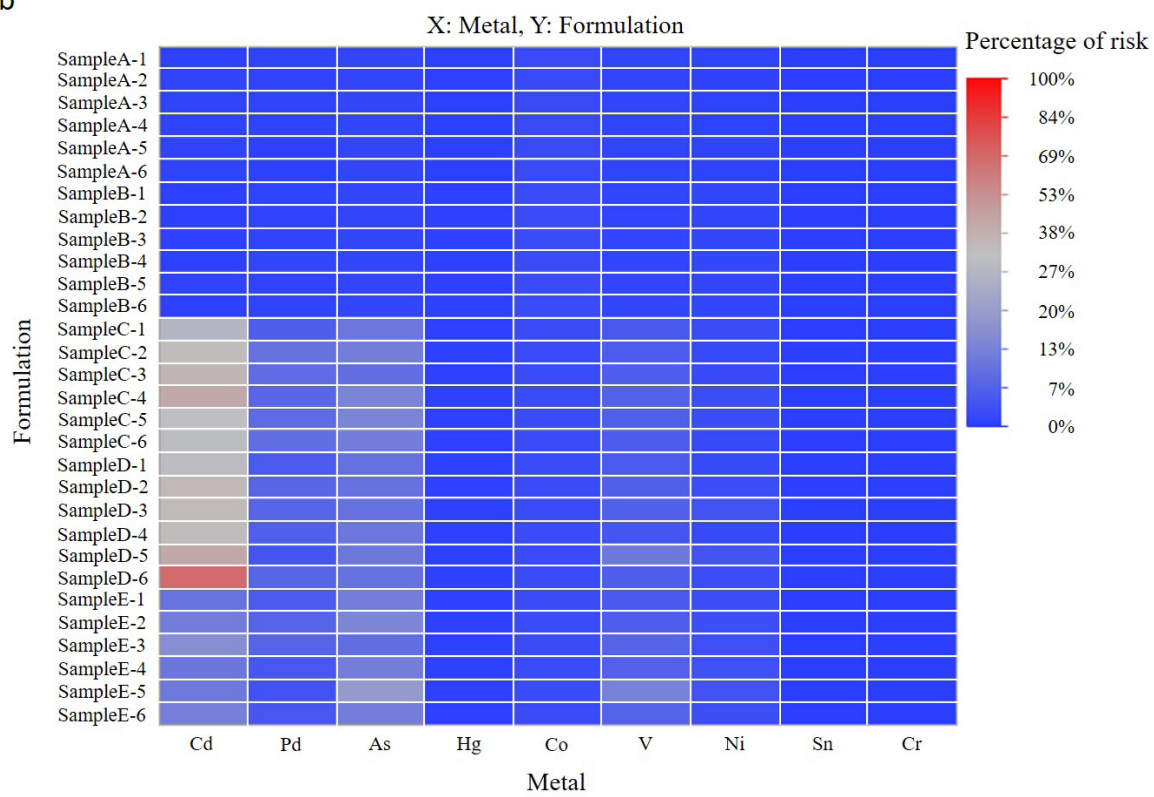

Figure 2. Cluster analysis based on the $30 \%$ control threshold for heavy metal contents of each magnesium oxide preparation. The dataset in Figure 1 was used for the cluster analysis. (a): Hierarchical cluster analysis showing the presence of two major groups. (b): Heat map obtained by cluster analysis. Red color shows high impurity and high risk, and blue color shows low impurity and low risk.

Figure 1 and presented as a heat map diagram (Figure 2). The color of the heat map was set to switch from blue to red at the $30 \%$ control threshold of PDE, which is the control threshold. Cluster analysis suggested that preparations A-E were classified into two clusters, preparations $\mathrm{A}+\mathrm{B}$ and preparations $\mathrm{C}+\mathrm{D}+\mathrm{E}$, or three clusters, preparations $\mathrm{A}+\mathrm{B}$, preparations $\mathrm{C}+\mathrm{D}$, and preparation E. Preparations A and B were shown to be low in metal impurities and to have a low risk of adverse events due to such impurities.

\section{Discussion}

Magnesium oxide preparations are pharmaceutical products containing metal elements. For their manufacture, magnesium is collected from nature as a raw material, then concentrated and purified. Therefore, to produce magnesium oxide pharmaceuticals for humans use, highly industrial technology is required, and it is important to monitor the various metal impurities mixed during both the purification of the raw magnesium and the subsequent commercial processing. In this study, we investigated whether the metal element impurities contained in the magnesium oxide preparations sold in Japan meet the standards specified in ICH-Q3D. We also conducted cluster analysis based on the control thresholds and the adverse effect risk of impurities for Class 1 (Cd, Pb, As, Hg), Class 2A (Co, V, Ni) and Class 
3 (Sn, Cr) of each preparation.

It was found that the contents of $\mathrm{Cd}, \mathrm{Pb}, \mathrm{As}$, and $\mathrm{Hg}$, which have strong toxicity, in the manufactured products, did not contravene the oral PDE standard (Table 4). However, $\mathrm{Cd}(0.71 \mu \mathrm{g} / \mathrm{g}), \mathrm{Pb}(0.18 \mu \mathrm{g} / \mathrm{g})$ and $\mathrm{As}(1.57$ $\mu \mathrm{g} / \mathrm{g})$ in preparation $\mathrm{C}, \mathrm{Cd}(0.83 \mu \mathrm{g} / \mathrm{g}), \mathrm{Pb}(0.13 \mu \mathrm{g} / \mathrm{g})$ and $\mathrm{As}(1.27 \mu \mathrm{g} / \mathrm{g})$ in preparation $\mathrm{D}$, and $\mathrm{Cd}(0.26 \mu \mathrm{g} / \mathrm{g})$, $\mathrm{Pb}(0.12 \mu \mathrm{g} / \mathrm{g})$ and $\mathrm{As}(1.70 \mu \mathrm{g} / \mathrm{g})$ in preparation $\mathrm{E}$ were present as elemental metal impurities. Their contents in preparations $\mathrm{C}, \mathrm{D}$ and $\mathrm{E}$ were significantly higher than those in preparations A and B, respectively $(p<$ $0.05)$. Data for the ADI of magnesium oxide calculated from the contents of $\mathrm{Cd}$ and $\mathrm{Pb}$ in preparations $\mathrm{C}$ and $\mathrm{D}$ showed that the ADI for $\mathrm{Cd}$ was $7.08 \mathrm{~g}$ /day (preparation C) and $6.00 \mathrm{~g} /$ day (preparation D) and that for $\mathrm{Pb}$ was $28.0 \mathrm{~g} /$ day (preparation C) and $38.0 \mathrm{~g} /$ day (preparation D). When magnesium oxide preparations are used as laxatives, the maximum daily dose for adults is $2 \mathrm{~g}$ /day as magnesium oxide, and therefore it can be said that none of these preparations exceeded the oral PDE value for $\mathrm{Cd}$. As the PDE value for $\mathrm{Pb}$ was exceeded when the highest-content preparation $\mathrm{C}$ was taken at $28.0 \mathrm{~g} /$ day or more, there would be no problem with the use of a normal amount of magnesium oxide, i.e. $2 \mathrm{~g} / \mathrm{day}$. Furthermore, the $\mathrm{Cd}$ and $\mathrm{Pb}$ contents of the magnesium oxide preparations $\mathrm{A}$ and $\mathrm{B}$ are less than one-fifth of those in preparations $\mathrm{C}, \mathrm{D}$ and $\mathrm{E}$, and thus preparations $\mathrm{A}$ and $\mathrm{B}$ are considered unlikely to cause health problems.

As an index of the significance of the measured values of elemental impurities, the ICH-Q3D guideline defines the $30 \%$ level of the PDE value as a control threshold, and states that this control threshold should be used as a criterion for determining the necessity of further control of the preparation ( 1 ). As shown in Figure 1 and Table 5, when magnesium oxide is used clinically at a maximum daily intake of $2 \mathrm{~g}$, the daily intake of $\mathrm{Cd}$ is $1.35-2.12 \mu \mathrm{g}$ for preparation $\mathrm{C}$ and $1.51-3.43 \mu \mathrm{g}$ for preparation D. Five lots of preparation $\mathrm{C}$ and all lots of preparation $\mathrm{D}$, tested in this study exceeded the $30 \%$ control threshold of $1.5 \mu \mathrm{g}$. This suggests that for preparations $\mathrm{C}$ and $\mathrm{D}$, it would be necessary to establish further control strategy to ensure that the PDE value is not exceeded.

In this study, based on the ICH-Q3D guidelines, risk classification based on the elemental metal impurity content of each of preparations A-E was attempted by cluster analysis. As shown in Figure 2, this demonstrated two clusters - preparations $\mathrm{A}+\mathrm{B}$ and preparations $\mathrm{C}+\mathrm{D}$ $+\mathrm{E}$ - or three clusters - preparations $\mathrm{A}+\mathrm{B}$, preparations $\mathrm{C}+\mathrm{D}$ and preparation $\mathrm{E}$. This also suggests that preparations A and B have low metal impurity contents and comply with the ICH-Q3D guidelines, presenting little risk to the living body. On the other hand, as shown in Figure 1 and Table 5, preparations $\mathrm{C}$ and $\mathrm{D}$ exceeded the $30 \%$ control threshold defined in the ICH-Q3D guideline, and preparations $\mathrm{C}+\mathrm{D}$ were those considered to warrant additional management methods to ensure that their oral PDE value was not exceeded.

$\mathrm{Cd}$ exists in mineral form in nature and is obtained mainly from $\mathrm{Cd}$ ore for commercial use (7). $\mathrm{Cd}$ is used as a catalyst in organic synthesis, and the problem with oral exposure is nephrotoxicity (8). Therefore, the PDE value is set at $5 \mu \mathrm{g} /$ day using the evaluation index for nephrotoxicity.

$\mathrm{Pb}$ exists in nature as both organic and inorganic forms. Organic $\mathrm{Pb}$ compounds are decomposed fairly quickly in the atmosphere and remain as inorganic $\mathrm{Pb}$ compounds in water and soil. In humans, exposure to $\mathrm{Pb}$ can affect neural, reproductive, developmental, immune, cardiovascular and renal function. In general, susceptibility to $\mathrm{Pb}$ toxicity is higher for exposure during the fetal period and childhood than during adulthood. In addition, epidemiological data suggest that blood $\mathrm{Pb}$ levels below $5 \mu \mathrm{g} / \mathrm{dL}$ may be associated with neurobehavioral disorders in children (9). Based on these findings, the $\mathrm{PDE}$ value of $\mathrm{Pb}$ was set at $5 \mu \mathrm{g}$ /day. Considering the nephrotoxicity of $\mathrm{Cd}$ and $\mathrm{Pb}$ mentioned above, this point should be taken into consideration when taking magnesium oxide preparations at doses higher than those stated in the package insert or in the case of long-term administration.

As is ubiquitous in the environment and found in food, soil, drinking water and the atmosphere. Inorganic As exists as trivalent (arsenic trioxide, sodium arsenate, etc.) or pentavalent (sodium arsenic, arsenic pentoxide, arsenic acid, etc.) forms and is highly toxic in the trivalent state. The state of the element is therefore important. Since organic As is also contained in seawater, it is abundant in seaweed. Since the toxicity of organic As is lower than that of inorganic As, and the latter is related to contamination of pharmaceutical products, the standard for safety evaluation is set for inorganic As. It is reported that ingestion of drinking water containing high doses of sodium arsenate by pregnant female rats significantly increased the incidence of liver cancer in next-generation male rats (10). Inorganic As is known to be a carcinogen to humans (11). Oral intake of As is associated with skin, liver, lung, kidney and bladder cancer. The PDE value when taken orally is set at $15 \mu \mathrm{g} /$ day based on the chronic effect of As on the skin. In this study, the As content was highest for preparation $\mathrm{E}$ at 1.70 $\mu \mathrm{g} / \mathrm{g}$, followed by preparation $\mathrm{C}$ at $1.57 \mu \mathrm{g} / \mathrm{g}$, but both met the standard PDE value and there was only a small possibility of health hazards due to chronic toxicity.

$\mathrm{Hg}$ is widely distributed in the global environment and exists in three forms: metallic, inorganic and organic $\mathrm{Hg}$. The form of $\mathrm{Hg}$ remaining in drug preparations is usually inorganic $\mathrm{Hg}$. Therefore, safety assessment of $\mathrm{Hg}$ has been based on toxicological data for metallic $\mathrm{Hg}$ and inorganic Hg. The International Agency for Research on Cancer (IRC) has concluded that the carcinogenicity of inorganic $\mathrm{Hg}$ to humans does not fit into the previous classification (12). Although inorganic $\mathrm{Hg}$ exhibits lower bioavailability via oral ingestion than organic $\mathrm{Hg}$, 
it has various toxic effects such as neurological effects, corrosiveness, hematopoietic and renal effects, and advanced pain in skin diseases. The underlying toxicity of safety standards for inorganic $\mathrm{Hg}$ and its salts is nephrotoxicity. The PDE value for $\mathrm{Hg}$ was $30 \mu \mathrm{g} / \mathrm{day}$, and the $\mathrm{Hg}$ content of all the preparations in this survey was less than $0.05 \mu \mathrm{g} / \mathrm{g}$, which was below the detection limit.

Co, which is classified as Class $2 \mathrm{~A}$, is a constituent element of vitamin B12 and an essential element acting as a coenzyme in hemoglobin synthesis. However, cobalt sulfate and other water-soluble Co salts may be carcinogenic to humans. In the case of repeated oral administration, erythrocytosis is the most common problem. Co is classified as Class 2A, because it is associated with heavy metal pneumoconiosis, asthma and contact dermatitis upon inhalation exposure $(13,14)$. The PDE value at the time of oral administration was set at $50 \mu \mathrm{g} / \mathrm{day}$, but in this study, the content of all of the preparations was less than $0.50 \mu \mathrm{g} / \mathrm{g}$, which was not problematic.

$\mathrm{V}$ exists in the Earth's crust in various oxidized states. $\mathrm{V}$ classified into Class $2 \mathrm{~A}$ as vanadium pentoxide has a carcinogenic risk to humans (7). The gastrointestinal tract, cardiovascular system and blood system are the main targets of its toxicity by oral administration to humans, and the PDE value is set at $100 \mu \mathrm{g} /$ day. In this study, the $\mathrm{V}$ contents of preparations $\mathrm{C}, \mathrm{D}$ and $\mathrm{E}$ were 2.47-3.12 $\mu \mathrm{g} / \mathrm{g}$, being higher than those of preparations $\mathrm{A}$ and $\mathrm{B}$ at less than $0.50 \mu \mathrm{g} / \mathrm{g}$. However, all of the preparations were below the PDE value, and thus considered safe.

No report has indicated $\mathrm{Ni}$ carcinogenicity as a result of oral administration (15). High oral intake can cause stomach pain, weight loss and adverse effects on the blood and kidneys. It has also been reported that oral intake of $\mathrm{Ni}$ in drinking water induces dermatitis in humans (16). The PDE value was set to $200 \mu \mathrm{g} /$ day, but all the products measured this time were below the PDE value and there was no problem.

Since Sn contained in pharmaceutical preparations contains more inorganic $\mathrm{Sn}$ than organic $\mathrm{Sn}$, the safety evaluation is based on inorganic Sn. The problematic adverse effect of repeated oral administration is anemia (17). The PDE value for $\mathrm{Sn}$ is $6,000 \mu \mathrm{g} / \mathrm{day}$, and the $\mathrm{Sn}$ content of preparations A-E was less than $0.50 \mu \mathrm{g} / \mathrm{g}$, which was not considered problematic.

Since Class 3 classified $\mathrm{Cr}(6+)$ has strong oxidizing power, Cr-induced skin disorders and carcinogenicity have been confirmed (18). Cr contained in pharmaceutical products is often in the form of $\mathrm{Cr}$ (0) or $\mathrm{Cr}(3+)$ rather than the highly toxic $\mathrm{Cr}(6+)$. Therefore, drug safety assessments are based on $\mathrm{Cr}(3+)$ toxicity information, and $\mathrm{Cr}(6+)$ is excluded. Since no obvious health effects of oral intake of $\mathrm{Cr}(3+)$ have been identified, it is classified as Class 3. According to this measurement, the concentrations of $\mathrm{Cr}$ in preparations B-E were relatively high, with the exception of preparation A. However, since the oral PDE value was set as high as $11,000 \mu \mathrm{g} / \mathrm{day}$, the results for all the preparations were far below the PDE value, and it was considered that there was no problem.

Various potential sources of elemental impurities are: 1) Residual impurities resulting from elements added intentionally (e.g., catalysts) in the production of the drug substance, excipients, or other drug product components. 2) Elemental impurities that are not added intentionally and are potentially present in the drug substance, water, or excipients used in the preparation of the drug product. 3) Elemental impurities can be potentially introduced into the drug substance and/ or drug product from manufacturing equipment. 4) Elemental impurities that have the potential to be leached into the drug substance and drug product from container closure systems. Risk assessment of the drug substance should address the potential for inclusion of elemental impurities in the final drug product. The reason why the content of metal element impurities differed between the various surveyed preparations is considered to be that magnesium oxide is a compound that is affected by the conditions used for sampling of the raw material. Since the standard PDE value was not exceeded in any of the investigated preparations, there would be no problem if the daily dose was maintained within that stated in the package insert. However, for $\mathrm{Cd}, 5$ lots of preparation $\mathrm{C}$ and all lots of preparation D exceeded the control threshold. From the viewpoint of risk management, it is necessary to carry out further controls such as changing the steps of the manufacturing process, setting standard values for additives and raw materials, or selecting an appropriate container plugging system for these preparations. In addition, the levels of metal impurities in preparations $\mathrm{C}, \mathrm{D}$ and $\mathrm{E}$ showed were higher except for $\mathrm{Hg}$, Co and $\mathrm{Sn}$ in preparations $\mathrm{A}$ and $\mathrm{B}$, and the amount exceeded the dose stated in the package insert when the effect of magnesium oxide was insufficient. Therefore, an effect on the human body resulting from long-term administration, or administration to patients with renal impairment, cannot be ruled out. In this context, the present survey clarified that preparation A or B would be desirable in terms of the safety of its heavy metal content.

Currently, there are many generic drugs on the market that can reduce development costs in the pharmaceutical industry. In addition, the Ministry of Health, Labor and Welfare has a policy of promoting the transition from branded drugs to generic drugs with the aim of reducing national medical expenses. As products of the same drug diversify, even equivalence of efficacy and effect is guaranteed, the content of elemental metal impurities will vary depending on the raw materials and additives used by various pharmaceutical companies. Therefore, for long-term administration, it will be necessary to pay attention to accumulation of such impurities in the body. 
In order to ensure the globalization of the pharmaceutical industry and the safety of pharmaceutical products, it is considered necessary to conduct preparation tests based on ICH-Q3D in the future. As shown in this study, there may be preparations that meet the current standards but may not meet the ICH standards in the future. For preparations that may not meet these criteria, it will be necessary to seek improvement, and at the same time it is suggested that monitoring of impurities will be required when the ICH standard is introduced.

Funding: The study was funded by Kyowa Chemical Industry Co., Ltd.

Conflict of Interest: Mitsutoshi Satoh has received research grants from Kyowa Chemical Industry Co., Ltd. Hideki Maeda had been an employee of Astellas Pharma Inc. until September 2019.

\section{References}

1. International Council for Harmonisation of Technical Requirements for Pharmaceuticals for Human Use (ICH) GUIDELINE FOR ELEMENTAL IMPURITIES Q3D (R1). 2019. https://www.ema.europa.eu/en/ documents/scientific-guideline/international-conferenceharmonisation-technical-requirements-registrationpharmaceuticals-human-use_en-32.pdf (accessed May 6, 2021).

2. The Japanese Society of Gastroenterology. The guideline for chronic functional constipation. Nankodo, Tokyo, Japan. 2017; pp. 1-112. (in Japanese)

3. Koyama H, Satoh M, Tohyama C. Low dose exposure to cadmium and its health effects. (4) Body burden, critical concentration and life expectancy. Nihon Eiseigaku Zasshi. 2003; 57:624-635. (in Japanese)

4. World Health Organization (WHO). Environmental health criteria 165, inorganic lead, Geneva; 1995. https:// apps.who.int/iris/handle/10665/37241 (accessed May 6, 2021).

5. World Health Organization (WHO). Safety evaluation of certain food additives and contaminants, WHO food additive series: 44 (prepared by the 43rd meeting of the joint FAO/WHO expert committee on food additives (JECFA)). 2000. https://apps.who.int/iris/ handle/10665/44813 (accessed May 6, 2021).

6. Satoh M, Kamada A, Mitsuhashi N, Kasahara S, Iida K, Miyazawa S, Tanaka H, Kosugi T, Nishizawa K. Study on quality assurance for drug safety: Investigation of the content of heavy metal impurities in magnesium oxide preparations. Pharmacometrics. 2018; 95:1-7.

7. Agency for Toxic Substances and Disease Registry. Toxicological profile for vanadium, Public Health Service, U.S. Department of Health and Human Services, Atlanta, GA. 2012. https://www.atsdr.cdc.gov/toxprofiles/tp58.pdf (accessed May 6, 2021).

8. Buchet JP, Lauwerys R, Roels H, et al. Renal effects of cadmium body burden of the general population. Lancet. 1990; 336:699-702.

9. National Toxicology Program. Monograph on health effects of low-level lead, Health and Human Services U.S.
2012. https://ntp.niehs.nih.gov/ntp/ohat/lead/final/monogr aphhealtheffectslowlevellead_newissn_508.pdf (accessed May 6, 2021).

10. Waalkes MP, Ward JM, Liu J, Diwan BA. Transplacental carcinogenicity of inorganic arsenic in the drinking water: induction of hepatic, ovarian, pulmonary, and adrenal tumors in mice. Toxicol Appl Pharmacol. 2003; 186:7-17.

11. International Agency for Research on Cancer, World Health Organization, Lyon. Arsenic, metals, fibres, and dusts, a review of human carcinogens, monographs on the evaluation of carcinogenic risks to humans. 2012; 100: 41-85. https://monographs.iarc.who.int/wp-content/ uploads/2018/06/mono100C.pdf (accessed May 6, 2021).

12. International Agency for Research on Cancer, World Health Organization, Lyon. Beryllium, cadmium, mercury, and exposures in the glass manufacturing industry. Monographs on the evaluation of carcinogenic risks to humans. 1997; 58:239-346. https://publications.iarc.fr/ publications/media/download/1954/ed5ada49ff1536d147 4abdb982ee69583dbf1bc2.pdf (accessed May 6, 2021).

13. Agency for Toxic Substances and Disease Registry. Toxicological profile for cobalt, Public Health Service, U.S. Department of Health and Human Services, Atlanta, GA. 2004. https://www.atsdr.cdc.gov/toxprofiles/tp33-p. $p d f$ (accessed May 6, 2021).

14. International Agency for Research on Cancer, World Health Organization, Lyon. Cobalt in hard metals and cobalt sulfate, gallium arsenide, indium phosphide and vanadium pentoxide. 2006; 86:1-297. https://publications. iarc.fr/_publications/media/download/2705/29aacee6b89 ff816188dcd990b61a16ad6486eec.pdf (accessed May 6, 2021).

15. Heim KE, Bates HK, Rush RE, Oller AR. Oral carcinogenicity study with nickel sulphate hexahydrate in Fischer 344 rats. Toxicol Appl Pharmacol. 2007; 224:126137.

16. Nielsen GD, Søderberg U, Jørgensen PJ, Templeton DM, Rasmussen SN, Andersen KE, Grandjean P. Absorption and retention of nickel from drinking water in relation to food intake and nickel sensitivity. Toxicol Appl Pharmacol. 1999; 154:67-75.

17. De Groot AP, Feron V, Til H. Short-term toxicity studies on some salts and oxides of tin in rats. Food Cosmet Toxicol. 1973; 11:19-30.

18. International Agency for Research on Cancer, World Health Organization, Lyon. Risk of chemicals to humans, some metals and metallic compounds, monographs on the evaluation of carcinogenic monographs on the evaluation of carcinogenic risks to humans. 1980; 23:205324. https://publications.iarc.fr/_publications/media/ download/1571/e8a5d8c23ca32103f47ef366fa6b597491a 4d654.pdf(accessed May 6, 2021).

Received September 1, 2021; Revised October 24, 2021; Accepted October 25, 2021.

*Address correspondence to:

Mitsutoshi Satoh, Faculty of Pharmaceutical Sciences, Meiji Pharmaceutical University, 2-522-1 Noshio, Kiyose, Tokyo 204-8588, Japan.

E-mail: satoh@my-pharm.ac.jp

Released online in J-STAGE as advance publication October 29, 2021. 